\section{Recurrent selection in common bean aiming at resistance to white mold in a greenhouse}

\section{Fernanda Souza Lopes ${ }^{1^{*}}$, Monik Evelin Leite ${ }^{2}$, Antonio Carlos Mota Porto ${ }^{1}$, Luciana Aparecida Miguel ${ }^{1}$, Vanessa de Oliveira Lima Reis ${ }^{1}$ and João Bosco dos Santos ${ }^{1}$}

\begin{abstract}
The objectives of this study were to estimate the genetic progress of mass selection for white mold resistance in common bean, evaluated in a greenhouse in cycle XII of recurrent selection (900 $S_{0}$ plants), and compare it with field selection in previous cycles. In addition, progress was compared with microsatellite marker-assisted selection (MAS) among $S_{0: 1}$ progenies. The 79 most resistant $S_{0: 1}$ were evaluated under field conditions using a $9 \times 9$ simple lattice design; the 21 best $S_{0: 2}$ and those selected from cycles IX, X, and XI were evaluated in a $6 \times 6$ triple lattice. Genetic progress was $4.25 \%$ per cycle, and $12.17 \%$ between cycles XI and XII, showing higher selection efficiency in the greenhouse. The phenotypic gain and gain from assisted selection among the $S_{0: 1}$ progenies were 5.08 and $1.57 \%$, respectively, and the low value of MAS was due to only two markers (BM189 and BMD20) explaining the resistance.
\end{abstract}

Keywords: Phaseolus vulgaris L., Sclerotinia sclerotiorum, gain from selection, phenotypic selection, QTL, marker-assisted selection.

\section{INTRODUCTION}

Brazil is one of the largest producer and consumer of dry edible bean/common bean (Phaseolus vulgaris L.) in the world (Barbosa and Gonzaga 2012). However, the crop is highly affected by phytopathogenic organisms that highly damage it. White mold (Sclerotinia sclerotiorum) is one of the diseases that have most limited production in irrigated areas (Carvalho et al. 2013).

To reduce progression of this pathogen, fungicides must be used, together with management techniques, such as decreasing the use of irrigation and fertilizers. More upright plants with a more open canopy also aid in limiting white mold. In addition, lower plant density is sometimes recommended to reduce the disease (Vieira et al. 2012). However, the use of more resistant cultivars can contribute to disease control and higher bean grain yield. One difficulty is the polygenic nature of resistance of common bean to white mold, with moderate to low heritability. In this context, a procedure that has been effective in improving this trait is recurrent selection, based on successive cycles of intercrosses and evaluation and selection of superior individuals (Leite et al. 2016). In addition, selection assisted by molecular markers can increase genetic gain from selection, especially mass selection in $\mathrm{S}_{0^{\prime}}$, since it aims to prevent the problems associated with phenotypic selection.
Crop Breeding and Applied Biotechnology 19: 95-101, 2019 Brazilian Society of Plant Breeding. Printed in Brazil http://dx.doi.org/10.1590/198470332019v19n1a13

70332019v19n1a13

(n)




\section{FS Lopes et al.}

The use of DNA markers may facilitate selection, as they are non-destructive and able to mark several genes (QTLs Quantitative Trait Loci). Moreover, the markers can be tested using a single DNA sample in the seedling phase, without the need for several evaluations. However, the QTL $\times$ environment interaction and the inefficiency of identification of traits by markers may make assisted selection of little use. Thus, the objective of this study was to compare the efficiency of molecular marker-assisted selection to phenotypic selection regarding resistance of common bean to white mold, and to estimate gain from phenotypic selection in a greenhouse in cycle XII of recurrent selection and compare it with previous cycles.

\section{MATERIAL AND METHODS}

The experiment was conducted in an experimental area, in a greenhouse, and in the Laboratory of Molecular Genetics of the Department of Biology (DBI) of the Federal University of Lavras (Universidade Federal de Lavras - UFLA), Lavras, Minas Gerais, Brazil. The recurrent selection program for resistance of common bean to white mold began in the 2009/2010 crop season (Leite et al. 2016). Initially, 12 lines and/or cultivars were intercrossed, and the A195 cultivar was inserted in the second cycle (Table 1). Subsequently, in cycle VII, five new sources of resistance adapted to the region $(14,15,16,17,18)$ were inserted, and the three least promising progenies were removed from the intercross population. Until cycle $\mathrm{XI}$, mass selection in the $\mathrm{S}_{0}$ generation was performed in the field after inoculation of the plants.

The first cycle $\left(C_{0}\right)$ was obtained by crossing each parent with two others and, in the $F_{2}$ population, all plants were inoculated and evaluated, and the most resistant plants were selected. Cycle I ( $\left.C_{1}\right)$ was obtained by crossing the plants selected from each population with those selected from two other populations. From $\mathrm{C}_{1}$, the segregating 4-week $S_{0}$ plants were inoculated, evaluated, and selected, and then they were intercrossed. Using this procedure, one recurrent selection cycle takes only one crop season, and three cycles per year were set up until cycle IX $\left(C_{9}\right)$. The $S_{0}$ populations of $C_{10}$ were obtained from the 20 most resistant $\mathrm{S}_{0}$ plants of $\mathrm{C}_{9}$ from each one of the 15 progenies, which were intercrossed, evaluated, and selected in the same way as was performed in previous cycles. The same procedure was used for obtaining the $C_{11}$.

In this study, $900 \mathrm{~S}_{0}$ plants of cycle XII of recurrent selection were used, obtained from intercrossing the 15 progenies selected in cycle XI for resistance to white mold. The inoculum of S. sclerotiorum was obtained from an aggressive isolate (isolate 27), which began to be used in $\mathrm{C}_{7}$ and was identified in previous experimental assays. Three days after the second multiplication, mycelium inoculation was carried out in $\mathrm{S}_{0}$ plants of approximately 28 days of age using micropipette tips in a greenhouse with humidity around $90 \%$. For inoculation, the apexes of two stems per plant were sectioned at about $2.5 \mathrm{~cm}$ from the node, and the tip with the agar disc containing the mycelium was placed using the straw test method (Singh et al. 2014). Eight days after inoculation, each plant was evaluated based on mean reaction to white mold, using a diagrammatic scoring scale from 1 (absence of symptoms) to 9 (maximum infection or dead plant) (Singh et al. 2014). In the $S_{0}$ generation, a phenotypic negative mass selection was performed based on the mean of the evaluation using two branches per plant.

The $\mathrm{S}_{0: 1}$ and $\mathrm{S}_{0: 2}$ progenies selected, derived from the $\mathrm{S}_{0}$ plants of cycle XII, were evaluated in field experiments, and artificial inoculation was set up in both with isolate 27 . The $9 \times 9$ simple lattice experimental design, with 79 progenies and two controls (cultivar Cornell 605, which is resistant to wild mold according to Griffiths (2009), and "IPR Corujinha", 
a susceptible cultivar), were used in evaluations of the $\mathrm{S}_{0: 1}$ progenies in 2015. The cultivar IPR Corujinha belongs to the commercial carioca group, and it was used as a control in a previous study performed the Universidade Federal de Lavras. A $6 \times 6$ triple lattice was used to evaluate the $21 \mathrm{~S}_{0: 2}$ progenies selected in 2016, the same two controls, and the 13 best progenies selected from cycles IX, X, and XI ( 3 progenies from cycle IX, 5 from cycle X, and 5 from cycle XI). All the progenies selected were previously intercrossed to obtain the subsequent cycles. Each plot was represented by a one-meter-length row in the $S_{0: 1}$ generation, where 15 seeds were sown and 10 plants were inoculated per plot. In $S_{0: 2^{\prime}}$ the plot had a two-meter row, and 10 plants per plot were also inoculated. The other crop treatments were the same as normally used for the common bean crop.

The DNA of the $S_{0}$ plants of cycle XII was extracted according to the method used by Pereira et al. (2007). Microsatellite primers that identified QTLs of bean resistance to white mold were used (Table 2). The amplification products were separated by electrophoresis, using $6 \%$ polyacrylamide gel in TBE buffer ( $0.045 \mathrm{M}$ Tris-Borate and $0.001 \mathrm{M}$ EDTA) at $270 \mathrm{~V}$ for about one hour. Subsequently, they were stained with silver nitrate and photographed by a digital camera.

The data of resistance to white mold of the progenies were subjected to analysis of variance per generation. The model $Y_{i j l}=\mu+p_{i}+r_{j}+b_{(j)}+e_{i j l}$ was adopted, where $Y_{i j l}$ refers to the observation of the plot that received treatment $\mathrm{i}$, in block $\mathrm{l}$, within replication $\mathrm{j} ; \mu$ is the overall mean of the experiment; $p_{i}$ is the random effect of treatment $\mathrm{i}$, in which $\mathrm{i}$ $=1,2,3, \ldots, n$ and $n$ is the number of progenies evaluated in each experiment and $p \sim N\left(0, \sigma_{p}{ }^{2}\right), \sigma_{p}{ }^{2}$ being the variance among the progenies; $r_{j}$ is the effect of the replication $j$, where $j=1$ and 2 in the $S_{0: 1}$ generation of cycle XII, and $j=1$, 2 and 3 in the $S_{0: 2}$ generation of the progenies of cycle XII and those selected in cycles IX, X and XI; $b_{I(j)}$ is the random effect of block I within the replication $\mathrm{j}$ and $\mathrm{b}-\mathrm{N}\left(0, \sigma_{\mathrm{b}}{ }^{2}\right), \sigma_{\mathrm{b}}{ }^{2}$ being the variance between blocks; and $e_{i j l}$ is the random effect of the experimental error associated with the observation $Y_{i j l}$ and $\mathrm{e} \sim \mathrm{N}\left(0, \sigma_{\mathrm{e}}{ }^{2}\right), \sigma_{\mathrm{e}}{ }^{2}$ being the residual variance. In the final experiment with the 4 cycles, the model used was $Y_{i j \mid k}=\mu+p_{i}+r_{j}+b_{(j)}+c_{k}+e_{i j,}$, in which the treatment effect $\left(p_{i}\right)$ was considered fixed, due to the lower number of progenies already selected from cycles IX, X, XI, and XII, as well as inclusion of the effect of the different cycles $\left(c_{k}\right)$. The SAS program was used for analysis of the phenotypic data.

The $\mathrm{h}^{2}$ (broad sense heritability) and the gain from progeny selection were estimated from the results of analysis of variance of the $S_{0: 1}$ generation. In the $S_{0: 2}$ generation, the five most resistant progenies of cycle XII were used, comparing them to the progenies selected in the previous cycles (IX, X, and XI) to estimate the genetic progress achieved through recurrent selection by linear regression.

Table 2. Microsatellite primers used in marker-assisted selection

\begin{tabular}{lccc}
\hline Primer & Source & Primer & Source \\
\hline PV-gaat001 & (Yu et al. 2000) & ATA9 & (Antonio et al. 2012) \\
GATS91 & (Gaitán-Solís et al. 2002) & (Díaz and Blair 2006) \\
BM156 & (Gaitán-Solís et al. 2002) & BMc5 & (Benchimol et al. 2007) \\
BM172 & (Gaitán-Solís et al. 2002) & IAC 07 & (Benchimol et al. 2007) \\
BM175 & (Gaitán-Solís et al. 2002) & (Benchimol et al. 2007) \\
BM184 & (Gaitán-Solís et al. 2002) & (Benchimol et al. 2007) \\
BM189 & (Gaitán-Solís et al. 2002) 27 & (Benchimol et al. 2007) \\
BM197 & (Gaitán-Solís et al. 2002) & (Benchimol et al. 2007) \\
BMD15 & (Blair et al. 2003) & IAC 37 45 & (Benchimol et al. 2007) \\
BMD20 & (Blair et al. 2003) & IAC 51 & (Benchimol et al. 2007) \\
PVBR189 & (Souza et al. 2016) & IAC 63 & (Benchimol et al. 2007) \\
PVBR93 & (Grisi et al. 2007) & IAC 71 & (Benchimol et al. 2007) \\
PVESTBR221 & (Garcia et al. 2011) & IAC 74 & (Buso et al. 2006) \\
PVESTBR279 & (Garcia et al. 2011) & IAC 77 & (Buso et al. 2006) \\
PVESTBR42 & (Lara et al. 2015) & IAC 98 & (Grisi et al. 2007) \\
PVESTBR73 & (Souza et al. 2016) & (YC et al. 2000) \\
SSR-IAC134 & (Cardoso et al. 2008) & PVBR 21 & (Blair et al. 2009) \\
SSR-IAC159 & (Cardoso et al. 2008) & PVBR 23 & (Gaitán-Solís et al. 2002) \\
ATA7 & (Antonio et al. 2012) & PVBR 78 & PVag003 \\
\hline
\end{tabular}


To verify genetic gain from assisted selection, a stepwise multiple regression analysis with the polymorphic markers in the $S_{0: 1}$ progenies was performed, using the SAS software (SAS Institute 2011). In order to obtain the selection differential based on the markers used to estimate the gain expected from marker-assisted selection (MAS), the 16 progenies with all the QTL markers were selected. Later, the gain obtained from MAS was compared to the gain obtained from phenotypic selection to identify the most efficient method, through the procedure proposed by Hamblin and Zimmermann (1986):

$\%=\frac{A-C}{M-C}$, in which $C$ corresponds to $5 \%$ of the number of selected progenies, $A$ to the number of progenies selected by MAS, and $\mathrm{M}$ to the total number of progenies selected.

\section{RESULTS AND DISCUSSION}

\section{Evaluation of the resistance of $\mathrm{S}_{0: 1}$ and $\mathrm{S}_{0: 2}$ progenies to white mold by the straw test}

The estimate of broad sense heritability of $31.16 \%$ suggests reduced genetic variation among the means of the $\mathrm{S}_{0: 1}$ progenies of cycle XII. The means may have been uniform in relation to resistance because the phenotypic selection used in $\mathrm{S}_{0}$ was very efficient, reducing the variability in $\mathrm{S}_{0: 1}$. Regarding evaluation of the resistance of $S_{0: 2}$ progenies to white mold by the straw test, reduced variation among the progenies was once more observed, and high experimental precision is indicated by the coefficient of variation (CV) and accuracy (Table 3). However, regression analysis of the means obtained from the progenies selected from the four cycles had a coefficient of determination $\left(R_{2}\right)$ of $93.54 \%$, indicating that the adjusted regression model explained the data variation (Figure 1).

There were significant differences $(P<0.05)$ among the 5 groups (CIX, CX, CXI, CXII, and control) (Table 3), between the controls and cycles, among the progenies of cycle XII, and between the controls. The high genetic heterogeneities mentioned were influenced by the two controls, which were highly contrasting (Table 4). Although there was no difference among the means of the progenies from the four cycles, the differences detected among the progenies of cycle XII indicates that among them are some other more susceptible plants, since a higher number of progenies was evaluated in this generation.

There was genetic progress of $-4.25 \%[(b 1 / b 0) 100$, Figure 1] per cycle, considering cycles IX to XII, i.e., the means of the progenies decreased by 0.215 per cycle of recurrent selection. The negative value of genetic progress is due to reduction in the means during the cycles, and the resistance is due to the lower scores. If we consider only the gain of cycle XII in relation to cycle XI (12.17\%), it proved to be higher than the other gains, indicating the superiority of mass selection in the greenhouse compared to the experiment in the field for the $\mathrm{S}_{0}$ of the previous cycles. This fact contributed to reduction in variability among the progenies of cycle XII shown in Tables 3 and 4.
Table 3. Analysis of variance of the reaction to white mold of the $S_{0: 2}$ progenies, and the result of linear regression involving the five best progenies of cycle XII and the others evaluated, and the respective genetic gains of the progenies obtained from selection and $\mathrm{R}^{2}$

\begin{tabular}{lcll}
\hline Sources of variation & df & MS & Fc \\
\hline Rep & 2 & 1.224 & $8.83^{*}$ \\
Block (Rep) & 15 & 0.102 & 0.73 \\
Group (Cycles + Control) & 4 & 1.402 & $10.11^{*}$ \\
Cycles & 3 & 0.154 & 1.11 \\
Control vs Cycles & 1 & 4.658 & $33.59^{*}$ \\
Progenies (P) & 31 & 0.496 & $3.58^{*}$ \\
P (C-IX) & 2 & 0.102 & 0.74 \\
P (C-X) & 4 & 0.037 & 0.27 \\
P (C-XI) & 4 & 0.216 & 1.55 \\
P (C-XII) & 20 & 0.422 & $3.04^{*}$ \\
Control & 1 & 5.704 & $41.13^{*}$ \\
Error & 54 & 0.139 & \\
\hline Mean progenies CXII & & 3.012 & \\
CV (\%) & & 12.36 & \\
Accuracy (\%) & & 84.89 & \\
Gain per cycle & & -0.215 (6.67\%) \\
$\mathrm{R}^{2}$ adjusted & & 0.9354 & \\
\hline
\end{tabular}

*: Significant at $5 \%$ probability by the $\mathrm{F}$ test.

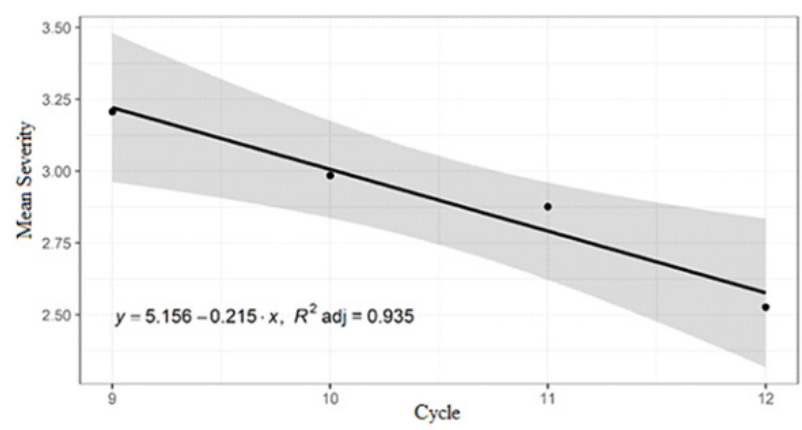

Figure 1. Linear regression of mean reactions to white mold of the progenies selected in the respective recurrent selection cycles $\mathrm{IX}, \mathrm{X}, \mathrm{XI}$, and XII. 
Table 4. Clustering of means of the progenies from cycles IX to XII [Scott-Knott (1974); P = 5\%]

\begin{tabular}{|c|c|c|c|c|c|}
\hline Cycle & Progeny & Mean & Cycle & Progeny & Mean \\
\hline & IPR Corujinha (T) & $5.11 \mathrm{a}$ & CXII & $56 \backslash 8$ & $2.97 \mathrm{c}$ \\
\hline CXII & $63 \backslash 8$ & $3.88 \mathrm{~b}$ & CXI & $11 \backslash 261$ & $2.93 \mathrm{c}$ \\
\hline CXII & $62 \backslash 9$ & $3.60 c$ & $\mathrm{CIX}$ & $26 \backslash 15$ & $2.93 c$ \\
\hline CXII & $64 \backslash 1$ & $3.52 \mathrm{c}$ & $C X$ & 10\107 & $2.91 \mathrm{c}$ \\
\hline $\mathrm{CIX}$ & $23 \backslash 7$ & $3.41 \mathrm{c}$ & CXI & $11 \backslash 364$ & $2.91 \mathrm{c}$ \\
\hline CXII & $61 \backslash 12$ & $3.41 \mathrm{c}$ & CXII & $64 \backslash 14$ & $2.90 \mathrm{c}$ \\
\hline $\mathrm{CIX}$ & $34 \backslash 3$ & $3.25 c$ & CXII & $64 \backslash 5$ & $2.85 \mathrm{c}$ \\
\hline CXII & $56 \backslash 7$ & $4.19 \mathrm{c}$ & CXII & $53 \backslash 10$ & $2.81 \mathrm{c}$ \\
\hline$C X$ & $10 \backslash 19$ & $3.19 \mathrm{c}$ & CXII & $59 \backslash 8$ & $2.78 \mathrm{c}$ \\
\hline CXII & $64 \backslash 9$ & $3.16 \mathrm{c}$ & $C X$ & $10 \backslash 267$ & $2.73 \mathrm{c}$ \\
\hline CXI & $11 \backslash 296$ & $3.05 \mathrm{c}$ & CXII & $56 \backslash 5$ & $2.40 \mathrm{c}$ \\
\hline$C X$ & 10\185 & $3.00 \mathrm{c}$ & CXI & $11 \backslash 185$ & $2.36 \mathrm{c}$ \\
\hline
\end{tabular}

The clustering of the mean reactions of the progenies regarding resistance to white mold was performed using the Scott-Knott (1974)'s clustering test from the $S_{0: 2}$ generation evaluation (Table 4). There were three distinct groups: the first, with only the control cultivar "IPR Corujinha", which was the most susceptible to white mold, as expected; the second group was also represented by only one progeny, which was the most susceptible of cycle XII; and the other progenies and the resistant control Cornell 605 constituted the most resistant group. In addition, once more, cycle XII had the highest number of progenies evaluated, and the uniformity among them was certainly due to the efficient mass selection applied in $\mathrm{S}_{0}$ in the greenhouse.

It is important to note that all the progenies have resistance similar to Cornell 605, which is one of the most important sources of resistance (Leite et al. 2016, Lehrner et al. 2016). They also have bean grains similar to the 'Carioca' cultivar (cream colored/beige seed coat with brown stripes), and most of them have an upright growth habit, which can contribute to increase disease control in the crop.

In addition to the accentuated gain obtained from mass selection in a greenhouse, the gains obtained from cycles IX to XII were higher than those observed in the initial cycles of the program (Leite et al. 2016), and certainly occurred as a consequence of the introduction of new sources of resistance in cycle VII. However, such gains were made possible due to the efficiency of recurrent selection, whereby the resistance alleles of the different sources could be recombined and reunited in the progenies, resulting in resistance levels higher than those of the original parents.

There are few studies on the use of recurrent selection for improving resistance to white mold in common bean. The gains obtained in the present study were two times higher than those obtained from selection of progenies descendant from double hybrids (Terán and Singh 2010a, b). A gain of 31\% in three cycles of recurrent selection was obtained by Lyon et al. (1987), which is higher than the result obtained in the present study. However, those authors performed interspecific crosses, using Phaseolus coccineus as a source of resistance, which is highly resistant to white mold.

\section{Efficiency of marker-assisted selection}

Of the 38 pairs of microsatellite primers used (Table 2), only two (BM189 and BMD20) were efficient in the stepwise multiple regression analysis to aid in selection of $S_{0: 1}$ progenies with higher resistance to white mold, but they explain only $16.81 \%$ of the variation observed in their means (Table 5).

Only 15 of the markers used showed polymorphism among the progenies. Although these markers were previously 
Table 5. Genetic and phenotypic parameters related to selection of $\mathrm{S}_{0: 1}$ progenies and the efficiency of MAS compared to phenotypic selection of resistance to white mold

\begin{tabular}{lc}
\hline Genetic and phenotypic parameters & 31.16 \\
\hline Heritability of $\mathrm{S}_{0: 1}$ progenies (\%) & 16.81 \\
$\mathrm{R}^{2}$ adjusted (multiple regression) (\%) & 3.18 \\
Mean of the $79 \mathrm{~S}_{0: 1}$ progenies & 2.66 \\
Mean of the 16 best $\mathrm{S}_{0: 1}$ progenies & 3.02 \\
Mean of the 16 progenies derived from the MAS & $-0.1615(5.08 \%)$ \\
Gain from phenotypic selection & $-0.05(1.57 \%)$ \\
Gain from marker-assisted selection & $31.27 \%$ \\
Efficiency of marker-assisted selection in relation to phenotypic selection & \\
\hline
\end{tabular}

identified as QTL markers of resistance to white mold in common bean (Table 2), most of them did not explain the variation of the progenies related to the disease and, consequently, there was low efficiency in marker-assisted selection. Among the reasons mentioned by Liu (1998), non-detection of QTLs by markers may be due to the reduced population and non-detection of sufficient linkage disequilibrium between the markers and the QTLs. Another reason may be because the population is derived from several successive intercross cycles of the recurrent selection program and may have separated the markers from the QTLs. There is also the possibility that QTLs were not expressed under the conditions of this experiment since they were identified under different conditions. In addition, heritability of the reaction to white mold is not high, especially the heritability observed in this population. Because of mass selection in $\mathrm{S}_{0}$, the variation among the $\mathrm{S}_{0: 1}$ progenies has almost been exhausted.

According to these results, the efficiency of marker-assisted selection for resistance to white mold obtained by the expression proposed by Hamblin and Zimmermann (1986) was $4.76 \%$ (Table 5). From stepwise multiple regression analysis, 16 progenies containing the two markers or QTLs considered significant were identified, and only two of these progenies (56/5 and 56/7) were simultaneously selected by markers and by phenotypic selection, and both were used to compose the $S_{0: 2}$ generation (Table 5). Therefore, even under these conditions of reduced variability among the $S_{0: 1}$ progenies, the gain obtained from phenotypic selection was more than three times higher than that obtained from MAS. Mass selection in $\mathrm{S}_{0}$ in the greenhouse is more efficient than that performed under field conditions. The low efficiency of MAS compared to phenotypic selection of progenies mainly occurred due to the low variation in resistance among the progenies and due to the low number of markers expressed that were associated with the QTLs of resistance.

\section{ACKNOWLEDGMENTS}

Our thanks to FAPEMIG and CNPq for financial support and to CAPES for granting a scholarship to the first author.

\section{REFERENCES}

Antonio RP, Santos JB, Alves FC, Gonçalves PRC and Lara LAC (2012) Seleção assistida por marcadores de DNA em retrocruzamento visando resistência ao mofo branco em feijoeiro. Revista Caatinga 25: 61-67.

Barbosa FR and Gonzaga ACO (2012) Informações técnicas para o cultivo do feijoeiro-comum na região central-brasileira: 2012-2014. Embrapa Arroz e Feijão, Santo Antônio de Goiás, 19p.

Benchimol LL, Campos T, Carbonell SAM, Colombo CA, Chioratto AF, Formighieri EF, Gouvêa LRL and Souza AP (2007) Structure of genetic diversity among common bean (Phaseolus vulgaris L.) varieties of mesoamerican and Andean origins using new developed microsatellite markers. Genetic Resources and Crop Evolution 54: 1747-1762.

Blair MW, Pedraza F, Buendia HF, Gaitán-Solís E, Beebe SE, Gepts P and Tohme J (2003) Development of a genome-wide anchored microsatellite map for common bean (Phaseolus vulgaris L.). Theoretical and Applied Genetics 107: 1362-1374.

Blair MW, Torres MM, Giraldo MC and Pedraza F (2009) Development and diversity of Andean-derived, gene-based microsatellites for common bean (Phaseolus vulgaris L.). BMC Plant Biology 9: 100.

Buso GSC, Amaral ZPS, Brondani RPV and Ferreira ME (2006) Microsatellite markers for the common bean - Phaseolus vulgaris. Molecular Ecology Notes 6: 252-254.

Cardoso JMK, Oblessuc PR, Campos T, Sforça DA, Carbonell SAM, Chioratto AF, Formighieri EF, Souza AP and Benchimol LL (2008) New microsatellite markers developed from an enriched microsatellite common bean library. Pesquisa Agropecuária Brasileira 43: 929-936.

Carvalho RSB, Lima IA, Alves FC and Santos JB (2013) Selection of carioca common bean progenies resistant to white mold. Crop Breeding and 
Recurrent selection in common bean aiming at resistance to white mold in a greenhouse

Applied Biotechnology 13: 172-177.

Díaz LM and Blair MW (2006) Race structure within the Mesoamerican gene pool of common bean (Phaseolus vulgaris L.) as determined by microsatellite markers. Theoretical and Applied Genetics 114: 143-154.

Garcia RAV, Rangel PN, Brondani C, Martins WS, Melo LC, Carneiro MS, Borba TCO and Brondani RPV (2011) The characterization of a new set of EST-derived simple sequence repeat (SSR) markers as a resource for the genetic analysis of Phaseolus vulgaris. BMC Genetics 12: 1-7.

Gaitán-Solís E, Duque MC, Edwards KJ and Tohme J (2002) Microsatellite repeats in common bean (Phaseolus vulgaris): isolation, characterization and cross-species amplification in Phaseolus ssp. Crop Science 42: 2128-2136.

Griffiths PD (2009) Release of Cornell 601-606: Common bean breeding lines with resistance to white mold. HortScience 44: 463-465.

Grisi MCM, Blair MW, Gepts P, Brondani C, Pereira PAA and Brondani RPV (2007) Genetic mapping of a new set of microsatellite markers in a reference common bean (Phaseolus vulgaris) population BAT93 $\mathrm{x}$ Jalo EEP558. Genetics Molecular Research 6: 691-706.

Hamblin JE and Zimmermann MJO (1986) Breeding common bean for yield in mixtures. Plant Breeding Reviews 4: 245-272.

Lara LAC, Santos JB, Balestre M, Lima IA, Pamplona AKA, Veloso JS and Silva PH (2015) Identification of QTLs of resistance to white mold in common bean from multiple markers by using Bayesian analysis. Genetics and Molecular Research 4: 1124-1135.

Leite ME, Dias JA, Souza DA, Alves FC, Pinheiro LR and Santos JB (2016) Increasing the resistance of common bean to white mold through recurrent selection. Scientia Agricola 73: 71-78.

Lehner MS, Júnior TJP, Vieira RF, Lima RC, Soares BA and Silva RA (2016) Reaction of sources of resistance to white mold to microsatellite haplotypes of Sclerotinia sclerotiorum. Scientia Agricola 73: 184-188.

Liu HB (1998) Statistical genomics, linkage, mapping and QTL analysis.
CRC Press, Boca Raton, 611p.

Lyon ME, Dickson MH and Hunter JE (1987) Recurrent selection for resistance to white mold in Phaseolus species. Journal of the American Society for Horticultural Science 112: 149-152.

Pereira HS, Santos JB, Abreu AFB and Couto KR (2007) Informações fenotípicas e marcadores microssatélites de QTL na escolha de populações segregantes de feijoeiro. Pesquisa Agropecuaria Brasileira 42: 707-713.

SAS Institute (2011) SAS/STAT ${ }^{\circledR} 9.2$ User's guide. $2^{\text {nd }}$ edn, SAS Institute, Cary, 7869p.

Singh SP, Schwartz HF and Steadman JR (2014) A new scale for white mold disease rating for the common bean cut-stem method of inoculation in the greenhouse. Annual Report of the Bean Improvement Cooperative 57: 231-232.

Scott AJ and Knott MA (1974) A cluster analysis method for grouping means in the analysis of variance. Biometrics 30: 507-512.

Souza DA, Balestre M, Pamplona AKA, Leite ME, Dias JA and Santos JB (2016) White mold resistance-associated quantitative trait loci in the Jalo x Small White common bean population. Genetics and Molecular Research 15: 1124-1135.

Terán H and Singh SP (2010a) Recurrent selection for physiological resistance to white mold in dry bean. Plant Breeding 129: 327- 333.

Terán H and Singh SP (2010b) Gamete and recurrent selection for improving physiological resistance to white mold in common bean. Canadian Journal of Plant Science 90: 153-162.

Vieira RF, Júnior TJP, Carneiro JES, Teixeira H and Queiroz TFN (2012) Management of white mold in type III common bean with plants pacing and fungicide. Tropical Plant Pathology 37: 95-101.

Yu K, Park SJ, Poysa V and Gepts P (2000) Integrating of simple sequence repeat (SSR) markers into a molecular linkage map of common bean (Phaseolus vulgaris L.). Journal of Heredity 91: 429-434.

(cc) $\mathrm{EY}$ This is an Open Access article distributed under the terms of the Creative Commons Attribution License, which permits unrestricted use, distribution, and reproduction in any medium, provided the original work is properly cited. 